\title{
Ofício de carteiro e atividade: por uma gestão pelas variações
}

\author{
Cibele Vargas Machado Moro ${ }^{\mathrm{I}, 1}$ e Fernanda Spanier Amador ${ }^{\mathrm{II}, 2}$ \\ ${ }^{\text {I }}$ Empresa Brasileira de Correios e Telégrafos (Porto Alegre, RS) \\ II Universidade Federal do Rio Grande do Sul, Instituto de Psicologia, \\ Departamento de Psicologia Social e Institucional (Porto Alegre, RS)
}

\begin{abstract}
Neste artigo, propomo-nos analisar o trabalho do carteiro a partir do referencial da Clínica da Atividade e da Ergologia, buscando discutir a questão das instâncias gestionárias nesse contexto. Para tanto, partimos de entrevistas e acompanhamentos a carteiros realizados no trabalho de uma das autoras na Empresa Brasileira de Correios e Telégrafos. A análise aponta que, apesar das fortes prescrições que compõem o trabalho do carteiro, há um constante esforço de renormatização empreendido por esse profissional de forma a gerir a distância entre as dimensões prescrita e real do trabalho, bem como lidar com as variações e os imprevistos no seu dia a dia. A gestão micropolítica empreendida no curso da atividade é intensamente reportada a outros - colegas, clientes, gestores - e conduzida pela noção de eficácia, de forma a viabilizar o atingimento de metas e objetivos. Percebe-se também que diversos aspectos do ofício do carteiro compõem-se por meio de uma metodologia construída coletivamente, operada pelo tensionamento entre as contribuições estilísticas dos sujeitos e o gênero na atividade.
\end{abstract}

Palavras-chave: Trabalho, Carteiros, Atividade, Subjetividade, Saúde mental, Gestão.

The postman's occupation and activity: for a management through variations

In this article, we propose an analysis of a postman's occupation based on references from the Clinic of Ergology and Activities, aiming at discussing the issue of management levels in this context. For this, we start from interviews and tracking of postmen made by one of the authors at Empresa Brasileira de Correios e Telégrafos, the Brazilian Post Office. The analysis indicates that, despite the strong prescriptions that are part of a postman's occupation, there is a constant effort for re-normatization, undertaken by this professional, in order to manage the distance between the prescribed and the real dimensions of work, and also to deal with variations and unexpected events in his daily activities. The micropolitical management undertaken in the course of his activities is intensely reported to others colleagues, customers, managers - and it is driven by the notion of efficacy, so as to make it possible to achieve goals and objectives. It is also noted that several aspects of a postman's occupation come from a collectively constructed methodology, operated by tension between stylistic contributions by subjects and the gender in their activities.

Keywords: Work, Postmen, Activity, Subjectivity, Mental health, Management.

$E$ ste artigo parte da experiência de uma das autoras como psicóloga do trabalho na Empresa Brasileira de Correios e Telégrafos (ECT), atuando em atividades variadas, desde entrevistas de seleção em processos de recrutamento interno até acompanhamento de trabalhadores e desenvolvimento de equipes, passando pela participação em grupos de trabalho interdisciplinar. Nessa experiência, chamam-nos a atenção, em especial, as inúmeras facetas da relação entre o sujeito e o trabalho, o qual, para muito além de fonte de sofrimento abordagem que algumas teorias privilegiam -, constitui-se como espaço de autoria, reconhecimento e transformação. Isso é o que fica claro quando temos a oportunidade de acompanhar as atividades de um carteiro ou mesmo disponibilizar um espaço de escuta para as questões relativas ao seu trabalho. Acreditamos que essa abordagem do trabalho, que privilegia a dimensão potencializadora da vida em seus múltiplos aspectos, vai ao encontro dos

1 Psicóloga, especialista em instituições em análise.

2 Psicóloga, pós-doutora em educação. Professora do Departamento de Psicologia Social e Institucional do Instituto de Psicologia da Universidade Federal do Rio Grande do Sul. 
pressupostos da Clínica da Atividade e da Ergologia, motivo pelo qual adotamos essas teorias como referenciais às ideias aqui desenvolvidas. Assim, nosso objetivo será discutir o trabalho dos carteiros sob o ponto de vista da Clínica da Atividade e da Ergologia, abordando, ainda, a questão das instâncias gestionárias nesse contexto.

Remetendo à noção de trabalho como tendência criadora, Clot (2011) aponta a função psicológica do trabalho enquanto fonte de alteridade, iniciativa e criatividade, desde que permita a expansão do poder de agir do trabalhador ${ }^{3}$. Complementa, ainda, afirmando o papel insubstituível do trabalho no desenvolvimento pessoal, na construção do próprio valor e na contribuição do sujeito para a formação do patrimônio histórico-cultural humano (2006a). Dentro desse mesmo entendimento, Bendassolli e Soboll (2011) compreendem o trabalho como atividade por meio da qual o sujeito se afirma na sua relação consigo mesmo e com aqueles com quem trabalha, contribuindo também para a perpetuação de um ofício a partir de sua dimensão coletiva.

Ao considerarmos, ainda, que trabalhar inclui necessariamente a possibilidade de introduzir modificações na realização da tarefa, formas de criação e iniciativa (Fonseca \& Barros, 2010), acreditamos que tal concepção de trabalho está estreitamente relacionada à noção de subjetividade, conforme proposto por Tittoni e Nardi (2006), a qual está articulada, nesse contexto, aos modos como as experiências de trabalho configuram modos de agir, pensar, sentir e trabalhar, em determinados momentos, evocando conexões entre elementos, valores, necessidades e projetos diversos. Tais modos tensionam os modos de sujeição e de insubordinação nos contextos de trabalho e podem agenciar oportunidades de invenção de outras formas de trabalhar.

Para a discussão que nos propomos aqui, cabe, ainda, referirmos o entendimento de saúde mental que adotamos e que está atrelado à noção de trabalho na sua dimensão transformadora e de subjetividade enquanto processo sempre múltiplo. A ideia de saúde à qual nos referimos diz respeito, conforme Georges Canguilhem (1966, citado por Clot, 2006b), à possibilidade do sujeito ver-se como autor de novas normas de vida e instigar novas formas de viver a partir da mobilização que as trocas com seu meio provocam. Assim, saúde não se refere a um equilíbrio ou a uma simples adaptação ao meio, e sim a uma capacidade de enfrentar riscos, lidar com as variabilidades e, com isso, renormatizar seu meio. De acordo com Clot (2008), saúde relaciona-se, afinal, com a invenção e a permanente criação de normas.

É a partir desse aporte conceitual que vimos surgir as principais concepções da Clínica da Atividade (Clot, 2006a, 2010) e da Ergologia (Schwartz, 2000, 2004, 2011), abordagens centradas notadamente na noção de atividade. Parte-se do entendimento de que o trabalho prescrito - tarefa pré-definida, fixada por regras, que envolve a previsão de resultados a serem obtidos - não corresponde jamais ao trabalho real - aquele efetivamente realizado -, pois, no curso do desenvolvimento da ação, lida-se com imprevistos e variabilidades, ínfimas que sejam, impossíveis de serem antecipadas por completo. A atividade é compreendida, então, como o esforço intenso empreendido pelo trabalhador no sentido de gerir tais variabilidades, ou seja, a distância entre o prescrito e o real. Nesse esforço de gestão, há uma mobilização cognitiva e afetiva do trabalhador, o qual é convocado por inteiro, por meio de seu corpo biológico, sua inteligência, sua afetividade e sua história de vida e de relações com os outros. Foge-se, assim, da noção de que o trabalho corresponda, em qualquer caso, à mera execução (Borges, 2004).

A partir do envolvimento subjetivo do trabalhador na atividade, Clot (2006a) propõe que às tradicionais definições de trabalho prescrito e real se acrescente a noção de real da atividade, incorporando, além do que deve ser feito e do que efetivamente se faz, aquilo que não pode ser observado diretamente, como as esferas que, enquanto virtuais, aguardam para se atualizar em modos de trabalhar e, até mesmo, as vivências subjetivas dos trabalhadores no

3 O poder de agir é, para Yves Clot, central nas análises clínicas do trabalho. Trata-se de potência de ação, algo da ordem da criação (Clot, 2010). 
curso de sua atividade ${ }^{4}$. Essa categoria incluiria, assim, o que não se faz, o que não se pode fazer e o que se tenta fazer sem conseguir, além de outras (im)possibilidades e dos virtuais da atividade.

A necessidade de gestão das variabilidades no curso do trabalho e a mobilização subjetiva daí advinda podem ser relacionadas à ideia de uso de si, conforme proposto por Schwartz (2000). De acordo com o autor, o trabalho envolve necessariamente debates do sujeito consigo próprio na medida em que o trabalho real ultrapassa o prescrito e que, neste caso, o trabalhador acaba por se ver convocado a entrar em atividade. Para além do aparente, é convocado um espectro contínuo de recursos e capacidades infinitamente mais vasto que aqueles explicitados na tarefa. Daí a noção de uso de si por si, uma vez que o recentramento do meio se dá inevitavelmente a partir da singularidade de cada um, de microescolhas relacionadas às histórias de vida e aos valores do sujeito. Schwartz chama a atenção também para a possibilidade de uso de si pelos outros na atividade, uma vez que o trabalho é sempre, em parte, heterodeterminado por normas, prescrições e valores constituídos historicamente e que não dependem diretamente do uso que o sujeito faz de si.

O trabalho, enquanto espaço que provoca problematizações e solicita constantemente arbitragens e microdecisões, envolve mudanças que, mesmo em pequena escala, acabam por colocar a norma em questão e por ressituá-la. As renormatizações são consideradas, assim, fato universal do qual não se pode fugir e envolvem a avaliação pelo sujeito do uso que faz de si próprio, alimentando as dramáticas de si (Schwartz, 2011). Por dimensão dramática da atividade compreende-se a obrigação posta ao trabalhador de repensar suas escolhas, de produzir o saber, de se situar em um mundo de valores, gerindo, dessa maneira, sua atividade de determinado modo. Tais escolhas e saberes remetem a pessoa a ela própria e ajudam na construção de determinado ofício, na medida em que criam uma situação racionalmente inantecipável.

A possibilidade de o sujeito contribuir com o trabalho a partir de sua singularidade, de seu potencial inventivo, intervindo ao mesmo tempo sobre o mundo e sobre si mesmo, é tratada por Yves Clot pelo conceito de poder de agir. A expansão da capacidade de agir dos trabalhadores sobre as situações vivenciadas (incluindo a atividade, si próprio e a atividade dos outros), coletiva e individualmente, assume um papel fundamental na Clínica da Atividade, sendo considerado o maior interesse dessa abordagem (Bendassolli \& Soboll, 2011; Clot, 2006b, 2011). Por outro lado, quando a atividade está impedida e não se tem a possibilidade de criar e modificar, diz-se que há uma perda - ou amputação - do poder de agir. Desse desenvolvimento impedido emergiria o sofrimento do sujeito (Lhuilier, 2011; Teixeira \& Barros, 2009).

A dimensão coletiva do trabalho também é outro aspecto bastante valorizado no âmbito na Clínica da Atividade e da Ergologia. Schwartz (2011) situa o coletivo como importante aspecto do viver em saúde no trabalho, já que, para ele, as renormatizações envolvem, em alguma medida, uma gestão coletiva a partir do compartilhamento de valores comuns. Considera, ainda, que é pela cooperação dos coletivos de trabalho que dois importantes pontos são garantidos: as necessidades técnicas, que asseguram a produtividade, e a expressão positiva de vidas e histórias singulares a partir dos coletivos informais (Schwartz, 2000). Já no bojo teórico da Clínica da Atividade, o entendimento do trabalho como espaço de conservação e transmissão, bem como de invenção e renovação, envolve as noções de gênero e estilo como operadores fundamentais (Clot, 2006a). Gênero refere-se ao patrimônio de saberes informais gerados na experiência, situados para além da prescrição e compartilhados pelo coletivo, fornecendo recursos para enfrentar situações generalizadas em um ofício. Trata-se de uma memória transpessoal que vincula os trabalhadores como coautores de regras impessoais, as quais definem o uso dos objetos e o intercâmbio entre as pessoas em determinado meio. $\mathrm{O}$ gênero mantém-se pelas contribuições estilísticas, ou seja, o estilo pessoal que cada trabalhador

4 Empregamos o termo "virtuais" enquanto forças em vias de atualização, as quais remetem diretamente ao "estar em atividade" (Amador, 2009). 
imprime no desenvolvimento da ação. A estilização da atividade, a partir de reformulações do gênero por parte dos trabalhadores, faz que esse último seja tomado como um processo, como algo permanentemente em movimento, e o ofício seja sempre passível de transformação. Dessa maneira, enquanto o gênero momentaneamente estabilizado constitui-se como um meio de apropriação do trabalho, de pertencimento a um grupo e orientação a uma ação, o estilo é resultante de múltiplas experiências vividas, reformula o gênero e o transforma em recurso para a ação (Clot, 2006a, 2011; Teixeira \& Barros, 2009).

Dessa forma, a partir dessas importantes contribuições conceituais da Clínica da Atividade e da Ergologia, as noções de subjetividade e saúde são enriquecidas quando as tomamos em perspectiva aos conceitos aqui apresentados. Nesse contexto, compreendemos que tomar o trabalho sob a perspectiva da atividade significa colocar em pauta a noção de produção de subjetividade a partir da reinvenção do mundo e do próprio sujeito nos processos de trabalho (Fonseca, 2003). A saúde, portanto, estaria associada à possibilidade de expansão da vida, criação de um contexto para viver, e, em última análise, seria tomada como sinônimo de atividade, como propõe Yves Clot (2011).

\section{Subjetividade e trabalho postal}

Na revisão bibliográfica realizada ${ }^{5}$, foram encontrados poucos trabalhos que abordam a questão da subjetividade do trabalhador carteiro e colocam em análise sua relação com o trabalho (Betts, 2006; Patuzzi, 2000; Rossi, Calgaro \& Melo, 2007; Zanchet, 2007). A maior parte deles são textos não publicados, desenvolvidos por pessoas que realizavam prática acadêmica em psicologia do trabalho nos Correios, propondo, assim, uma discussão teórica a respeito de sua experiência. Inúmeros outros estudos sobre o trabalho do carteiro foram encontrados, contudo enfocavam apenas questões referentes à saúde física e à otimização de processos em serviços postais. Tais apontamentos já nos dão pistas sobre como, em termos de produção de conhecimento, pouco a psicologia tem se ocupado das questões subjetivas desse ofício.

O único texto publicado que encontramos referente à dimensão da subjetividade no trabalho do carteiro diz respeito a um estudo exploratório e descritivo realizado por Rossi, Calgaro e Melo (2007), os quais buscaram pesquisar sobre a saúde de carteiros, adotando como base a organização do trabalho, as condições e relações socioprofissionais, as vivências de prazer-sofrimento e os danos físicos e psicossociais. A pesquisa, que se baseou no referencial da psicodinâmica do trabalho, utilizou escalas com o intuito de avaliar o risco de adoecimento no trabalho e contou com a participação de 85 carteiros. Os principais resultados indicam que a saúde desses trabalhadores encontra-se em situação de risco, especialmente em relação às condições e à rigidez da organização do trabalho. Os autores apontam a rigidez das tarefas prescritas, as cobranças por pressão do tempo, o dispêndio físico e o uso intenso da memória e da concentração como aspectos do trabalho que incidem negativamente sobre a saúde do trabalhador. Além disso, verificou-se um dispêndio emocional relacionado pelos autores ao estresse gerado pela pressão para cumprimento de horários, de prazos, pelo temor de errar e pelas cobranças da chefia imediata. Por outro lado, foram encontrados altos índices de solidariedade entre colegas, o que, juntamente com a liberdade para utilizar o estilo pessoal na realização das tarefas, foi relacionado a sentimentos de prazer no trabalho.

Em outro estudo encontrado sobre o caráter subjetivo do ofício de carteiro, Patuzzi (2007) propõe discutir a organização do trabalho e sua possível relação com o sofrimento

5 A pesquisa foi realizada entre $1^{\text {o }}$ de maio e 30 de junho de 2011 em bases de dados nacionais (periodicos.capes.gov.br) e internacionais (regional.bvsalud.org, scielo.org). Os termos utilizados na pesquisa foram "carteiro", "subjetividade", "saúde" e "atividade" (e suas respectivas traduções para o espanhol, o francês e o inglês). 
psíquico. A partir da realização de um estudo de caso, a autora aponta alguns aspectos do trabalho que parecem especialmente atrelados às vivências de sofrimento: altos níveis de exigência de rapidez e precisão, bem como de recursos de atenção e capacidade de memorização, controle exacerbado das atividades internas e externas e individualização e fragmentação das tarefas. A autora menciona, ainda, que as situações de acidentes de trabalho - como os ataques de cães e acidentes envolvendo veículos -, a não consideração pelas singularidades e grandes exigências físicas no desempenho das atribuições da profissão acabam por resultar igualmente em elevada carga psíquica, a qual pode vir a se constituir em fonte de insatisfação e sofrimento psíquico.

Outro estudo foi desenvolvido por Zanchet (2007) por meio de uma pesquisaintervenção com um grupo de carteiros, utilizando recursos fotográficos como dispositivo para reflexão sobre o trabalho. As dificuldades encontradas pelos trabalhadores durante a entrega, tais como falta de numeração, altas escadas, ataques de cães e condições climáticas adversas dias de chuva ou calor intenso -, foram aspectos que tiveram destaque na fala dos carteiros. Além disso, estiveram bem presentes o ritmo acelerado em busca da entrega do maior número possível de objetos e a preocupação excessiva com o tempo, denotando altos níveis de ansiedade. Nesse sentido, a autora utiliza uma metáfora, propondo pensar o resto, a sobra (ou seja, os objetos não entregues), como aquilo que justamente pode subjetivar as pessoas, aquilo que faz questão. Ao concluir, ela aponta a urgência de espaços, nesse contexto, que agenciem o refletir e o questionar sobre o trabalho.

A pesquisa de Betts (2006), por outro lado, procurou analisar o significado de ser carteiro para o trabalhador e as vivências de prazer e sofrimento nesse ofício, partindo do referencial teórico da psicodinâmica do trabalho. A relação com os clientes e o fato de trabalhar na rua destacaram-se nas entrevistas realizadas. Diversos carteiros referiram sentimentos de satisfação e gratificação em relação ao contato com o público, ao entregar uma correspondência aguardada pelo cliente ou mesmo prestar informações solicitadas. Também atrelada às vivências de prazer esteve a satisfação por administrar o trabalho, já que na rua podem imprimir seu ritmo e seu jeito de desempenhar as tarefas, o que permite, segundo a autora, a adaptação do trabalho às aspirações e competências de cada um. Quanto às vivências de sofrimento, tiveram destaque a sobrecarga de trabalho, a responsabilidade sobre os objetos gerando receios quanto à possibilidade de extravio - e as dificuldades de adaptação no início do trabalho. Já o significado de ser carteiro esteve bastante atrelado novamente à relação com a população, na medida em que os trabalhadores referem perceber seu ofício como um lugar reconhecido pela sociedade como tendo valor e depositário de confiança e respeito.

\section{Trabalho prescrito no ofício de carteiro}

Tendo em vista que a análise de qualquer atividade a partir do referencial aqui adotado pressupõe necessariamente algum conhecimento a respeito do ofício em questão, propomo-nos a seguir apresentar alguns dos principais aspectos presentes no dia a dia de trabalho do carteiro, considerando, especialmente, nesse momento, a dimensão do trabalho prescrito, do previsto e do planejado previamente. É importante também apontar algumas observações em relação à dimensão técnica dessa atividade, em grande parte prevista pelo Manual de Distribuição dos Correios (MANDIS), que regulamenta as normas de distribuição de objetos postais pela empresa.

Parte importante do tempo de trabalho do carteiro é dedicado a uma etapa que antecede e organiza o momento da entrega: a triagem dos objetos postais, composta de três etapas distintas. Em um primeiro momento, cada carteiro realiza a triagem geral (TG), 
separando as cartas em grupos de distritos (áreas de entrega) a partir de seu código de endereçamento postal (CEP). Depois, a equipe realiza o "dominó", passando em fila pelo escaninho de cada colega e recolhendo a carga do distrito por cuja entrega é responsável. Para iniciar a próxima etapa, será necessário que todos os colegas tenham concluído a triagem de seu distrito. Assim, as equipes costumam considerar que essa etapa influencia seu trabalho tanto em termos de tempo (quanto mais rápida a triagem, mais cedo se iniciará e, portanto, se concluirá a entrega) quanto de qualidade, já que erros de separação nessa primeira triagem tendem a comprometer as etapas seguintes.

$\mathrm{Na}$ segunda etapa, a separação por logradouros (SL), cada carteiro, de posse de toda a carga de seu distrito, inicia a separação por ruas dentro de sua área de entrega, a partir do nome das ruas ou dos CEPs específicos de seu distrito. Quando cada um conclui a SL, dá-se início à última etapa de triagem da carga, o ordenamento. Nesse momento, cada carteiro passa a ordenar os objetos postais na sequência em que fará a entrega, o que dependerá das especificidades do local. Ele pode, por exemplo, realizar primeiro a entrega em todos os pontos de apenas um lado da rua e, somente depois, efetuar a entrega do outro lado. Nesse caso, diz-se que a entrega é realizada em forma de "U"; assim, será necessário separar os pontos de entrega de números pares dos ímpares, considerando-se também se o ordenamento será crescente ou decrescente em cada lado, dependendo de onde se iniciar a distribuição. Mas a entrega também pode ser realizada em "Z", alternando-se a entrega entre os dois lados da rua.

É importante destacar, ainda, que entre os distritos de uma mesma unidade pode haver grande variabilidade em termos de percorrida, distância entre pontos de entrega, quantidade de cargas simples e registradas, características geográficas do local, distância entre a unidade e o início das entregas, quantidades de depósitos auxiliares, carga e até mesmo características dos clientes.

Para todas as atividades da área de distribuição, são previstos tempos e processos de operacionalização por meio de uma ferramenta chamada Sistema de Distritamento (SD), aplicada periodicamente em cada unidade. As mensurações realizadas pelo SD, a partir da contagem da carga, e processadas por especialistas da área operacional preveem os tempos médios de triagem e entrega para cada distrito, além de apontarem a necessidade de utilização de recursos como veículos para entrega, redimensionamento de distritos e até redução ou aumento do efetivo.

\section{Proposição de um ensaio}

Para a análise que aqui nos propomos, partiremos de relatos de carteiros a respeito de seu trabalho prestados à equipe de psicologia da ECT no decorrer de entrevistas de seleção em processos de recrutamento interno e acompanhamentos a trabalhadores e a equipes de trabalho. Nossa proposta é buscar uma aproximação aos conceitos da Clínica da Atividade e da Ergologia. Acreditamos que a utilização dos operadores conceituais de ambas as teorias pode nos oferecer subsídios para melhor compreender as especificidades da atividade dos trabalhadores carteiros, como os gêneros e as formas estilísticas aí presentes, permitindo-nos colocar em análise os espaços e as condições de criação nesse ofício, bem como as restrições ao poder de agir.

Partindo-se da concepção de que a análise do trabalho é inseparável de sua transformação - uma vez que envolve necessariamente a produção de sentidos pelos sujeitos envolvidos na ação, numa associação entre explicação e compreensão (Clot, 2006a) - e que, então, somente se pode falar a partir da atividade - e não de fora dela -, apontamos o limite da análise que nos propomos aqui. É importante esclarecer que este trabalho consiste em um 
ensaio de aproximação teórica e, por questões de operacionalização, não visa à utilização de ferramentas metodológicas de análise conforme proposto pelas abordagens teóricas mencionadas. Contudo, apesar de não partirmos da instauração de um dispositivo metodológico de análise junto aos trabalhadores, acreditamos que a aproximação proposta pode oferecer importantes pistas quanto à centralidade da atividade no contexto de trabalho dos carteiros.

\section{Ofício de carteiro: entre o prescrito e o real, a atividade postal}

Para falar sobre um trabalho realizado, é necessário ter em mente, antes de tudo, que esse real jamais pode ser apreendido em sua totalidade. $\mathrm{O}$ relato de um sujeito sobre seu próprio trabalho já é em si uma recriação, nunca correspondendo à experiência vivida. Clot (2006a) chama a atenção para o fato de a verbalização ou a evocação das operações vividas estar muito além de uma mera representação de eventos passados. Ele aponta, nesse contexto, o impacto do destinatário da verbalização na descrição da ação pelo sujeito, sendo relevantes as intenções presentes do sujeito para com os outros e para com ele próprio. Tratar-se-ia, assim, de uma criação psicológica nova a partir da vivência presente do sujeito em relação ao seu interlocutor. Em última análise, ao se reconsiderar o realizado e o real da atividade, estaria em jogo uma permanente recriação, uma possibilidade de enriquecimento da atividade que, se não permite $o$ acesso ao trabalho real, por isso mesmo lança o trabalho em um campo de possíveis. Essa compreensão é importante em relação tanto às situações trazidas pelos próprios carteiros ao nos relatarem as situações de seu trabalho quanto ao relato que aqui nos aventuramos. Nos dois níveis, são recriações sobre o realizado.

Nas falas dos carteiros, um aspecto bastante comum diz respeito à satisfação em relação ao trabalho externo, ou seja, ao período em que realizam as entregas domiciliares. Corroborando os apontamentos de Betts (2006), verificamos que essa etapa do trabalho costuma ser percebida como a que lhes permite maior autonomia e sensação de liberdade. A variabilidade das situações vividas, as diferenças entre clientes e regiões de entrega e os acontecimentos inesperados em sua percorrida diária convocam o carteiro permanentemente a uma gestão muito mais ativa de seu trabalho - e de si - do que no período de atividades internas, quando, mesmo realizando microdecisões, está à mercê das avaliações e controles diretos dos colegas e da chefia. Nesse sentido, um carteiro nos dizia que, na rua, "nenhum dia é igual ou mesmo parecido com o outro", dando-nos a noção de quanto de arbitragens lhe é solicitado.

Embora inúmeros aspectos da entrega estejam normatizados - como apontamos anteriormente -, na prática, o que se verifica é que o carteiro tem condições de readequar - e, de fato, renormatizar - certas prescrições conforme as especificidades diárias de seu trabalho. As readequações das formas de entrega (em Z, U etc.) são um exemplo disso. Geralmente, quando um carteiro inicia um novo distrito, é-lhe apresentada a sistemática de entrega em cada rua, indicada pelo Sistema de Distritamento $(\mathrm{SD})$ - e que poderia ou não estar sendo seguida pelo carteiro anterior. É comum que, na medida em que vai adquirindo maior conhecimento daquela região, o carteiro readapte a proposta de entrega de acordo com suas necessidades e com aquilo que ele avalia que é a maneira mais adequada. Nessas reavaliações, é comum também utilizar parte do sugerido pelo próprio SD, bem como pela experiência de outros colegas, compondo, assim, uma "metodologia coletiva" de trabalho. Assim, se tomássemos em análise apenas a entrega e somente em um distrito, já perceberíamos quanto a sistemática de trabalho ali adotada está atravessada por um histórico que inclui as contribuições estilísticas de diversos atores que foram delineando determinada maneira de trabalhar - ou um gênero -, a qual continua em permanente processo de reavaliação e sempre em relação com o instituído 
em termos de norma (SD). Essa "metodologia" construída coletivamente parte, assim, de renormatizações que envolvem o compartilhamento de valores comuns e colocam permanentemente o protocolo em manutenção (Schwartz, 2011).

Se, por um lado, a referência à autonomia na entrega é tão comumente relacionada a um sentimento de satisfação, por outro, a exposição sistemática a situações imprevistas e que envolvem grande mobilização subjetiva parece relacionada, em alguns casos, a um sofrimento psíquico. Lembramo-nos de uma situação em que fomos procuradas por um carteiro que, muito mobilizado emocionalmente, pensava em pedir demissão. Contava que vinha enfrentando situações com as quais não sabia como lidar: assaltos, ataques de cães, ameaças. Dizia que a gota d'água foi a ameaça que sofrera ao chutar um cão que havia tentado mordê-lo. Ao nos afirmar "Eu só queria entregar carta", sem sabê-lo, o carteiro fazia referência à dimensão do trabalho prescrito, colocando em perspectiva o real da atividade, o inesperado no contato com a realidade, sua mobilização subjetiva. A situação descrita faz emergir, assim, a função do sujeito como agente de seu próprio ato no trabalho, gerenciando os imprevistos que compõem o hiato entre o prescrito e o real (Bendassolli \& Soboll, 2011). A respeito disso, Lhuilier (2011) afirma que o ato coloca o sujeito em contato direto com o real e com uma parcela de risco inerente a toda atividade: risco de fracasso, de erro, de acidente - e, no caso dos carteiros, até mesmo de sofrer algum tipo de violência -, bem como risco de inventividade. A autora aponta, ainda, que é justamente o imprevisto contido nas situações que abre espaço para o desenvolvimento da subjetivação e para a expansão do poder de agir. Por outro lado, a partir da situação acima mencionada, são as situações inesperadas do trabalho, aquelas que fogem ao controle do trabalhador, que parecem também poder gerar limitações a esse poder. Assim, talvez possamos pensar que a questão central desse debate sobre o sofrimento não seja especificamente o imprevisto, e, sim, a impossibilidade de criar a partir dele. Nesse contexto, cabe refletirmos quanto os riscos, por vezes, de violência no trabalho podem paralisar o trabalhador - ainda que momentaneamente -, na medida em que impedem a atividade, tolhendo seu desenvolvimento e contribuindo para seu sofrimento.

Também a partir das situações acima referidas, podemos pensar na noção do uso dramático de si. Lidar com a violência em situações de trabalho, por exemplo, ainda que possa limitar em parte as possibilidades de ação do sujeito, exige, como qualquer outra situação inantecipável, que o sujeito faça uso de si próprio - mínimo que seja - na gestão da atividade. O trabalho enquanto espaço de tensões problemáticas supõe a convocação do sujeito em seu ser, a partir de seu capital pessoal. Dessa maneira, "apenas entregar cartas" só é possível como trabalho prescrito; no nível do real, muito mais é exigido do trabalhador, que necessita mobilizar de si muito além daquilo que a tarefa prevê (Schwartz, 2011). Essa "gestão micropolítica" no exercício da atividade (Fonseca \& Barros, 2010) envolve valores de vida e de saúde e o questionamento incessante do uso que fazemos de nós mesmos, como nos parece claro no exemplo que vimos discutindo.

Ao conversarmos com carteiros ou ao conhecermos suas atividades, percebemos um gerenciamento próprio e mais direto sobre diversos aspectos de seu trabalho. Em certa ocasião, um grupo de carteiros falava sobre um aspecto corriqueiro que costuma exigir-lhes soluções inventivas para viabilizar as entregas: os dias de chuva. Nessas situações, contavam-nos, é necessário o desenvolvimento de estratégias para proteger as encomendas e imprimir maior agilidade à entrega para compensar as adversidades do mau tempo. Para dar conta do manejo da bolsa, do guarda-chuvas, da lista de recebimento a ser assinada pelo cliente, necessitando, ainda, bater palmas para avisar sobre sua chegada, os carteiros entrevistados afirmavam lançar mão de diferentes estratégias, que iam desde diversos arranjos de sua indumentária até a customização da bolsa de forma a proteger os objetos postais da chuva. Assim como esses, diversos outros ajustes podem ser mencionados em relação ao desempenho de suas atribuições, e todos parecem estar relacionados com a busca de certo agir competente no trabalho. Uma situação que costuma suscitar inúmeros debates diz respeito à entrega em locais que não 
equivalem ao endereço constante na correspondência. Alguns carteiros assim procedem, por exemplo, em situações nas quais o cliente mudou de residência e ainda não atualizou seu novo endereço. Para evitar que a correspondência seja devolvida ao remetente (muitas vezes, são faturas com data próxima de vencimento), quando o novo endereço do cliente é conhecido pelo carteiro, este pode optar por fazer-lhe a entrega, ainda que a norma oriente a apenas entregar no local estabelecido na correspondência. Assim, fazer a entrega em local diverso daquele previsto pode significar o atendimento a uma necessidade (e satisfação) do cliente, alguém com quem o carteiro se relaciona diretamente no dia a dia e que parece compor um importante aspecto de sua própria satisfação com o trabalho. Da mesma maneira, o preenchimento do Aviso de Recebimento durante a entrega reduz o tempo de "baixa" no retorno à unidade e aumenta o período de entrega, atendendo às solicitações de produtividade. Todos esses rearranjos incluídos na atividade mostram-nos não apenas o caráter inacabado do trabalho e a necessidade constantemente posta aos trabalhadores de produzir novas normas, mas apontam para uma tentativa de eficácia, uma vez que atuam de forma a viabilizar o trabalho prescrito em termos de metas e objetivos, já que possibilitam, por exemplo, a entrega do maior número possível de objetos e ainda intactos. Nesse sentido, ao falar sobre as gestões individuais - no sentido de que cada trabalhador é gestor de seu próprio trabalho, pois faz uso de si na atividade -, Schwartz (2004) distingue o polo da eficácia (avaliação de um ato a partir de seus objetivos) e o polo da eficiência (avaliação do produto da atividade a partir dos meios disponíveis para alcançá-lo). O autor complementa que a operacionalização dos valores de eficácia e de eficiência depende das modalidades singulares da dramática de uso de si de cada sujeito, remetendo a normas de eficácia de seu si.

A partir dos exemplos citados, podemos pensar quanto o uso de si mobilizado pelos trabalhadores no plano micro de sua atividade está atravessado por um campo de valores que conduzem às escolhas a serem feitas. Também aparece em pauta a negociação dos usos de si, uma vez que, de um lado, se impõem as normas e as instruções operacionais (uso de si pelos outros) e, de outro, sua história de vida e valores (uso de si por si). Nesse contexto, a relação com o cliente parece marcar fortemente as noções de eficácia e compor um importante valor compartilhado coletivamente entre os carteiros, passando pela significação de seu trabalho, conforme o estudo de Betts (2006) já havia apontado ${ }^{6}$. Como Schwartz e Durrive (2010) assinalam, as respostas no trabalho são sempre em parte coletivas, reportando-se a "outros" sejam colegas, gestores, clientes -, os quais atravessam a atividade. Ao escolher determinado procedimento (como entregar ou não um objeto em endereço diferente daquele da correspondência), o trabalhador escolhe também a relação com os outros e com o mundo no qual quer viver. Assim, a dimensão coletiva da atividade, ao orientar as escolhas a serem feitas, acaba por se tornar também a fonte da performance e da eficácia - ou, pelo contrário, da ineficácia.

O caráter coletivo, ao que nos parece, perpassa durante todo o tempo a atividade. Algumas vezes, é observável mais diretamente e, em outras, está presente de maneira mais sutil, exigindo talvez uma atenção mais acurada, como no exemplo que acabamos de mencionar. Para a discussão que agora propomos, contudo, gostaríamos de focar, em especial, na dimensão coletiva interpares. No trabalho interno do carteiro, em que os resultados das etapas de seleção por logradouro e de ordenamento dependem da realização da triagem geral, da qual todos participam, percebemos que a atividade de um sujeito está entrelaçada à dos demais não apenas pela produtividade (rapidez e precisão) dos outros, mas também por tudo o mais que é compartilhado pela equipe - como a avaliação de métodos que "dão certo", ações que atrapalham, percepção de cooperação (ou não), posicionamento do grupo diante de uma carga excessiva, adoção de estratégias de resistência, entre tantos outros aspectos. Também o

6 A respeito desse aspecto que se refere à relação entre carteiros e sociedade, uma pesquisa realizada em 2010 pela GFK Custom Research Brasil apontou o carteiro como a segunda profissão mais confiável do país (92\%), ficando atrás apenas dos bombeiros, mencionados por 98\% dos entrevistados (Fonte: exame.abril.com.br/blogs/o-negocio-e-lista/2010/08/06/as-9-profissoes-maisconfiaveis-no-brasil/). 
trabalho externo, embora tenha um caráter mais "solitário", já que formalmente é realizado de maneira individual, não deixa por isso de ser igualmente permeado pelo coletivo. Inúmeros exemplos poderiam ser mencionados, mas gostaríamos de abordar duas situações que, acreditamos, são bastante esclarecedoras e podem trazer importantes elementos para nossa discussão.

Lembramo-nos do relato de um carteiro motorizado, que realizava suas entregas utilizando uma motocicleta. Ele contava que, embora as normas de distribuição previssem que o carteiro estacionasse o veículo e realizasse a pé as entregas nas redondezas, tinha claro que seu trabalho seria muito mais efetivo se não descesse da moto. $\mathrm{E}$ assim fazia, bem como outros colegas também motorizados, que obtinham o aval informal do gestor. A questão para ele - e possivelmente para os colegas - era otimizar as entregas (já que avaliava que, para pequenas distâncias, mais perdia tempo com o sobe-estaciona-desce da moto do que ganhava com a agilidade do veículo), mas também se sentir produtivo, eficiente. Tudo parecia ir bem até que começou a sentir dores nas costas e as relacionou às subidas nas calçadas. A partir daí, mudou seus procedimentos com o veículo, estacionando e descendo a cada entrega a ser feita. Logo, a diferença de desempenho foi sentida pela equipe e pelo gestor, que não tardaram a lhe questionar a mudança, a quebra de uma combinação tácita que vinha trazendo benefícios em termos produtivos e de autorreconhecimento.

A outra situação que gostaríamos de mencionar diz respeito a uma discussão que presenciamos em uma atividade de grupo com carteiros. Ao falarem sobre os procedimentos adotados na entrega, iniciou-se um intenso debate sobre o tempo de espera quando é necessária a assinatura do cliente no recebimento do objeto. Por um lado, alguns referiam preferir respeitar o tempo de espera previsto (três minutos para objetos registrados), afirmando o desejo de agradar ao cliente e, ainda, não ter sobrecarga no dia seguinte, já que, para objetos especiais, são previstas três tentativas de entrega. Por outro lado, havia carteiros que consideravam desnecessário aguardar tanto tempo, já que, se não eram atendidos no primeiro minuto, acreditam que possivelmente não havia ninguém em casa e que seria inútil aguardar mais. Assim, esperando pelo cliente menos tempo que o previsto, afirmavam ganhar tempo e poder atender a um montante maior de pessoas.

Ambos os exemplos, acreditamos, trazem à tona o entrelaçamento produzido no âmbito da atividade entre o particular - entendido como aquilo que a história produz em cada um de nós - e a cena coletiva, a partir de negociações que são sempre singulares. Colocam em perspectiva, assim, o ato de trabalho em função de laços, de antagonismos, de potencialidades que as relações sociais engendram (Schwartz, 2000). Afirmamos, desse modo, que a dimensão coletiva do trabalho não se reporta à produção de um fazer necessariamente igual, homogêneo, mas remete àquilo que é partilhado enquanto história coletiva e às possibilidades de negociação existentes no campo do trabalho, onde o outro está sempre presente. Trata-se, portanto, de uma noção em consonância com a viabilidade de colocar em circulação as diferenças, agenciando diferentes formas de estar no mundo.

Não se pode negar, entretanto, que a divergência produza, em alguns casos, conflitos em escalas variadas. Contudo, apesar de pressões e cobranças - e o consequente sofrimento que possam advir daí, como no exemplo do carteiro motorizado, chamamos a atenção para outro importante aspecto das discordâncias no âmbito do trabalho. De acordo com Clot (2008), é justamente a controvérsia que compõe o coletivo, e não a concordância, como se costuma pensar. Para ele (Clot, 2006b, 2011), a discussão e a confrontação são necessárias como fontes de energia vital e na medida em que desenvolvem o pensamento individual. Assim, o atravessamento do coletivo (ainda que na ordem da controvérsia) na atividade de cada sujeito mais uma vez evoca o permanente tensionamento entre as contribuições estilísticas e o gênero na atividade. Como parecem evidenciar os dois últimos exemplos citados, se o gênero remete a uma dimensão coletiva, do "em comum" no trabalho, ele também está aberto à expressão da singularidade de cada trabalhador e, por isso mesmo, é permanentemente 
colocado à prova pelo estilo, pelas contribuições do sujeito a partir de suas experiências (Clot, 2006a; Teixeira \& Barros, 2009). O gênero atua, então, como um ponto de referência para a ação do sujeito, ainda que seja para que ele faça seu trabalho de maneira totalmente outra mas sempre em referência ao gênero da atividade.

\section{Trabalho, instâncias gestionárias e saúde}

A partir de toda discussão realizada até aqui, pode-se pensar que, apesar das variadas prescrições que compõem o trabalho do carteiro, há um constante esforço de renormatização empreendido por esse profissional no seu dia a dia. Percebemos que, em muitas situações, tais renormatizações são de conhecimento do gestor e contam com seu aval - ainda que informal pois, como já comentamos, esses ajustes são fundamentais à viabilização do alcance das metas e dos objetivos. Incluímos aqui, então, um aspecto que consideramos bastante relevante, no contexto da Clínica da Atividade e da Ergologia: a dimensão das instâncias gestionárias - no sentido usual do termo - e sua relação com a variação da atividade.

Como mencionado, nossa experiência aponta que inúmeros gestores, por já terem atuado como carteiros e conhecerem muito bem a realidade do ofício, compreendem a necessidade dos rearranjos na atividade. Ocorre, entretanto, que a concordância (e às vezes, inclusive, o estímulo) do gestor em relação às renormatizações invariavelmente se passa em um nível não formal. Retomando o que Lhuilier (2011) aponta como a possibilidade de risco intrínseco à atividade, observamos que esse acordo tácito entre a equipe (incluindo-se aqui o gestor) parece funcionar bem quando ao risco se sucede a produção de um trabalho eficaz, exitoso. Por outro lado, quando o que se produz é da ordem de uma ineficácia ou uma dificuldade se impõe, percebemos que o acordo entre os diferentes atores não se sustenta. Diante da possibilidade de punição ou de outras retaliações, a ação do trabalhador muitas vezes acaba relegada a um nível de clandestinidade e de invisibilidade. Dessa maneira, concordamos com Fonseca e Barros (2010) quando mencionam que, na medida em que os macetes trazem o risco da ilegalidade, faz-se necessário a publicização dos atos técnicos para que haja o reconhecimento das habilidades e a legitimação das ações do sujeito.

Também as discordâncias entre os trabalhadores, ao mesmo tempo em que permitem colocar em análise os modos de gestão da atividade, apontam a importância da discussão do trabalho a partir da confrontação entre as prescrições e as singularizações. Como as autoras afirmam, o trabalho inventivo se realiza por redes de cooperação, sendo que uma arbitragem coordenada se dá com a construção de normas em que todos estejam engajados. Partindo disso, ressaltamos a necessidade de que a gestão do trabalho, que ocorre primeiramente em um plano micropolítico, expanda-se a planos mais macros, instaurando uma transversalidade entre trabalhadores de diferentes níveis e possibilitando a circulação coletiva de saberes e o agenciamento da eficácia, da saúde e da potência do ser no trabalho (Schwartz, 2011).

$\mathrm{Na}$ discussão entre as esferas prescritiva e real da atividade, parece fundamental incluir também a problematização do uso das ferramentas operacionais e da qualidade adotadas no âmbito do gerenciamento do trabalho. Se tivermos em mente as premissas básicas do nosso referencial teórico, o qual considera que o prescrito jamais corresponde ao real (Clot, 2006a) e que, portanto, a renormatização é inevitável (Schwartz, 2011), logo perceberemos que a questão das ferramentas, enquanto instrumentos para definição de normas de execução e de avaliação de desempenho, é problemática em si mesma. A padronização, entendida como uniformização da ação, só é possível teoricamente, e é fundamental que a gestão hierárquica compreenda a necessidade de uma flexibilização em torno dos parâmetros definidos. O caso do Sistema de Distritamento é bastante emblemático. Muitos carteiros questionam seus 
indicadores, pois acreditam que um sistema informatizado jamais poderá refletir a realidade com que deparam diariamente, a qual está em constante variação. Ainda que os indicadores de tempo e número de objetos a serem entregues sejam obtidos por meio de cálculos que preveem uma média - o que costuma ser apontado pela gestão como o caráter flexível do instrumento -, a ferramenta não tem a capacidade de antecipar as especificidades que um carteiro encontrará em um dia de entrega - como o tamanho de uma subida, a quantidade de cães, o número de casas sem caixa de correspondências etc.

Não estamos propondo com essa discussão que as normas sejam desconsideradas ou que deixem de existir. Sabemos que são os aspectos instituídos que conferem ao mundo uma estabilidade necessária à vida coletiva, mas reconhecemos também que a abertura ao movimento instituinte é necessária na busca da eficiência (Baremblitt, 2002) ${ }^{7}$. Assim, estamos de acordo com Schwartz (2011) quando ele afirma que não se trata de dissolver as normas antecedentes, mas que é necessário que se interrogue os saberes e as escolhas produzidas nas renormatizações e sua pertinência em relação ao inantecipável. Para o autor, também não se trata de eliminar os critérios quantitativos, mas os manter em condição de confrontá-los com suas lacunas. Acreditamos, dessa forma, que a norma deve estar aberta a revisão sistemática por meio da captação contínua de saberes, de modo que possa ser enriquecida e se reinstruir. No caso do trabalho postal, o acompanhamento pelo gestor das atividades internas e externas, por exemplo, tão reivindicada pelos carteiros, ganha importância fundamental, já que permite conhecer as especificidades desse ofício e pode auxiliar a enriquecer as normas antecedentes, como aquelas previstas pelas ferramentas operacionais. Nessa discussão, a partir do reconhecimento dos imprevistos e da diversidade das histórias humanas, inclusive a definição de competência merece ser retomada e pensada como resultado de uma habilitação intersubjetiva e social, que coloca em comunicação os saberes codificados e a história de vida, bem como a relação com o meio (Clot, 2006a; Schwartz \& Durrive, 2010).

Nesse contexto, pensamos o gestor hierárquico como alguém que desempenha um importante papel e que deve atuar para buscar viabilizar uma articulação que opere entre o molecular - plano instituinte das experiências, forças e potências - e o molar - plano instituído das normas e prescrições (Fonseca \& Barros, 2010). Nesse sentido, tendo presente que (1) a produção somente é possível pelo desenvolvimento da intelectualidade, da inteligência prática e da afetividade do trabalhador (Borges, 2004) e que (2) a possibilidade de inventividade nos contextos de trabalho é fundamental à saúde (Brito, 2004), concordamos com a proposta de Chanlat (2011) em relação a uma gestão compreensiva e reflexiva, que torne possível o equilíbrio entre a dinâmica social e as exigências econômicas. $O$ gestor surge, então, como alguém que deve dar passagem às singularidades e aos desejos criacionistas de suas equipes, buscando articulá-los aos objetivos do trabalho por meio do agenciamento de espaços que permitam colocar em questão a gestão micropolítica da atividade e seus desdobramentos.

Para que essa concepção de gestão seja possível, é necessário que se legitimem espaços de reflexão e discussão sobre o trabalho, a partir de uma abordagem dialógica em que a linguagem atue como mediadora do grupo e torne visíveis os esforços de gestão dos trabalhadores em relação às adversidades e imprevistos no curso da atividade. Como refere Chanlat (2011), os espaços para circulação da palavra podem auxiliar a reduzir a distância entre prescrito e real e criar condições para uma gestão hierárquica mais próxima das exigências do campo. Além disso, ao se partir do polo da experiência dos trabalhadores, das normas por eles criadas, e ampliar suas alternativas de escolha, é possível produzir as bases efetivas para a promoção de saúde dos sujeitos, afirmando, ao mesmo tempo, o processo de trabalho como biopolítico (Brito, 2004; Fonseca, 2003).

7 Conforme Baremblitt (2002), o instituído diz respeito ao resultado do processo instituinte e cumpre importante papel histórico ao ordenar as atividades sociais necessárias à vida do coletivo. Contudo, possui uma tendência a permanecer imutável, tornando-se resistente e conservador. Por outro lado, o instituinte define o processo mobilizado por forças produtivo-desejantes-revolucionárias, cuja tendência é fundar ou transformar as instituições. 
No contexto da Empresa Brasileira de Correios e Telégrafos, percebemos que ainda há um longo caminho a percorrer no que concerne ao engendramento de tais espaços de reflexão e discussão quanto à gestão micropolítica da atividade, bem como quanto à transversalidade da problematização do trabalho entre diferentes níveis hierárquicos. Contudo, algumas ações que vêm sendo iniciadas (como um projeto de cogestão, elaborado pela diretoria regional do Rio Grande do Sul) encorajam-nos a depositar grandes expectativas quanto a consideração e aprofundamento de uma abordagem ética-estética-política do trabalho na ECT, não apenas quanto ao ofício do carteiro, mas também em relação a todos os demais das diferentes áreas da empresa.

Para finalizar, gostaríamos de destacar, a partir do que vimos discutindo, o potencial alcance político da Clínica da Atividade, na medida em que gesta em si a possibilidade de transformação de formas instituídas ao expandir a análise da atividade para o plano macropolítico. Acreditamos na força política do referencial aqui adotado, inclusive quanto à transformação de aspectos referentes a organização do trabalho e funcionamento das organizações, desde que se criem estratégias que reforcem ações coletivas e transversais de análise do trabalho. Acreditamos, então, em uma Clínica do Trabalho que aposta na potência dos trabalhadores, na força pulsante da vida, agenciando diferenças nos modos de trabalhar, produzindo variações em modos de ser e viver.

\section{Referências}

Amador, F. S. (2009). Entre prisões da imagem, imagens da prisão: um dispositivo tecno-poético para uma clínica do trabalho. Tese de Doutorado, Instituto de Psicologia, Universidade Federal do Rio Grande do Sul, Porto Alegre.

Baremblitt, G. (2002). Compêndio de análise institucional e outras correntes: teoria e prática. Belo Horizonte: Instituto Felix Guattari.

Bendassolli, P. F. \& Soboll, L. A. (2011). Introdução às clínicas do trabalho: aportes teóricos, pressupostos e aplicações. In P. F. Bendassolli \& L. A. Soboll (Orgs.), Clínicas do trabalho: novas perspectivas para compreensão do trabalho na atualidade (pp. 3-21). São Paulo: Atlas.

Betts, M. K. (2006). Ser carteiro: relações entre significações, reconhecimento, prazer e sofrimento no trabalho. Monografia de estágio em psicologia do trabalho, Instituto de Psicologia, Universidade Federal do Rio Grande do Sul, Porto Alegre.

Borges, M. E. S. (2004). Trabalho e gestão de si: para além dos "recursos humanos". Cadernos de Psicologia Social do Trabalho, 7, 41-49.

Brito, J. (2004). Saúde do trabalhador: reflexões a partir da abordagem ergológica. In M. Figueiredo, M. Athayde, J. Brito \& D. Alvarez (Orgs.), Labirintos do trabalho: interrogações e olhares sobre o trabalho vivo (pp. 91-114). Rio de Janeiro: DP\&A.

Chanlat, J. F. (2011). O desafio social da gestão: a contribuição das ciências sociais. In P. F. Bendassolli \& L. A. Soboll (Orgs.), Clínicas do trabalho: novas perspectivas para compreensão do trabalho na atualidade (pp. 110 . 131). São Paulo: Atlas.

Clot, Y. (2006a). A função psicológica do trabalho. Petrópolis: Vozes.

Clot, Y. (2006b). Entrevista: Yves Clot. Cadernos de Psicologia Social do Trabalho, São Paulo, 9 (2), 99-107.

Clot, Y. (2008). Entrevista: Yves Clot. Mosaico: Estudos em Psicologia, Belo Horizonte, 2 (1), 65-70.

Clot, Y. (2010). Trabalho e poder de agir. Belo Horizonte: Fabrefactum.

Clot, Y. (2011). Clínica do trabalho e clínica da atividade. In P. F. Bendassolli \& L. A. Soboll (Orgs.), Clínicas do trabalho: novas perspectivas para compreensão do trabalho na atualidade (pp. 71-83). São Paulo: Atlas.

Fonseca, T. M. G. (2003). Trabalho, gestão e subjetividade. Arquivos Brasileiros de Psicologia, 55 (1), 2-11.

Fonseca, T. M. G. \& Barros, M. E. B. (2010). Entre prescrições e singularizações: o trabalho em vias de criação. Fractal: Revista de Psicologia, 22 (1), 101-114.

Lhuilier, D. (2011). Filiações teóricas das clínicas do trabalho. In P. F. Bendassolli \& L. A. Soboll (Orgs.), Clínicas do trabalho: novas perspectivas para compreensão do trabalho na atualidade (pp. 22-58). São Paulo: Atlas.

Patuzzi, J. B. (2007). O sofrimento psíquico no trabalho. Monografia de estágio em psicologia do trabalho, Centro de Ciências da Saúde, Universidade do Vale do Rio dos Sinos, São Leopoldo.

Rossi, E. Z., Calgaro, J. C. C. \& Melo, V. S. (2007). O trabalho dos carteiros no manuseio e na entrega de correspondências. In A. M. Mendes (Org.), Psicodinâmica do trabalho: teoria, método e pesquisa (pp. 325 344). São Paulo: Casa do Psicólogo. 
Schwartz, Y. (2000). Trabalho e uso de si. Pro-posições, 1 (5), 34-50.

Schwartz, Y. (2004). Trabalho e gestão: níveis, critérios, instâncias. In M. Figueiredo, M. Athayde, J. Brito \& D. Alvarez (Orgs.), Labirintos do trabalho: interrogações e olhares sobre o trabalho vivo (pp. 23-33). Rio de Janeiro: DP\&A.

Schwartz, Y. (2011). Manifesto por um ergoengajamento. In P. F. Bendassolli \& L. A. Soboll (Orgs.), Clínicas do trabalho: novas perspectivas para compreensão do trabalho na atualidade (pp. 132-166). São Paulo: Atlas.

Schwartz, Y. \& Durrive, L. (2010). Trabalho e ergologia: conversas sobre a atividade humana. Niterói: EDUFF.

Teixeira, D. V. \& Barros, M. E. B. (2009). Clínica da Atividade e Cartografia: construindo metodologias de análise do trabalho. Psicologia E Sociedade, 21 (1), 81-90.

Tittoni, J. \& Nardi, H. C. (2006). Subjetividade e trabalho. In A. D. Cattani \& L. Holzmann (Orgs.), Dicionário de trabalho e tecnologia (pp. 277-280). Porto Alegre: Editora da UFRGS.

Zanchet, L. (2007). O trabalho nosso de cada dia: imagens do ser carteiro: projeto de pesquisa e intervenção fotográfica. Monografia de estágio em psicologia do trabalho, Instituto de Psicologia, Universidade do Rio Grande do Sul, Porto Alegre.

\section{Endereço para correspondência}

cibelemachado@correios.com.br, fernanda.amador@ufrgs.br 